\title{
Emergency Nurses' Perceptions of Size, Frequency, and Magnitude of Obstacles and Supportive Behaviors in End-of-Life Care
}

\author{
Renea L. Beckstrand \\ Brigham Young University - Provo, renea@byu.edu \\ Michelle D. Smith \\ Sondra Heaston \\ Brigham Young University - Provo
}

\begin{abstract}
A. Elaine Bond
University of Jordan

Follow this and additional works at: https://scholarsarchive.byu.edu/facpub

Part of the Other Nursing Commons, and the Palliative Nursing Commons
\end{abstract}

\section{Original Publication Citation}

Beckstrand, R. L., Smith, M. D., Heaston, S., \& Bond, A. E. (2008). Emergency nurses' perceptions of size, frequency, and magnitude of obstacles and supportive behaviors in end-of-life care. Journal of Emergency Nursing, 34(3), 1-11.

\section{BYU ScholarsArchive Citation}

Beckstrand, Renea L.; Smith, Michelle D.; Heaston, Sondra; and Bond, A. Elaine, "Emergency Nurses' Perceptions of Size, Frequency, and Magnitude of Obstacles and Supportive Behaviors in End-of-Life Care" (2008). Faculty Publications. 5307.

https://scholarsarchive.byu.edu/facpub/5307

This Peer-Reviewed Article is brought to you for free and open access by BYU ScholarsArchive. It has been accepted for inclusion in Faculty Publications by an authorized administrator of BYU ScholarsArchive. For more information, please contact ellen_amatangelo@byu.edu. 


\title{
EMERgency Nurses' Perceptions of Size, Frequency, and Magnitude of Obstacles AND SUPPORTIVE BEHAVIORS IN END-OF-LIFE CARE
}

\author{
Authors: Renea L. Beckstrand, PhD, RN, CCRN, Michelle D. Smith, MS, NP-C, CEN, Sondra Heaston, MS, NP-C, \\ CEN, and A. Elaine Bond, DNSc, APRN, CCRN, Provo, Utah, and Amman, Jordan
}

Introduction: Emergency nurses care for dying patients daily. The process of dying in an emergency department can be complicated. Research on specific obstacles that impede the delivery of end-of-life care in emergency departments and behaviors that support it is limited.

Methods: A 70-item questionnaire was mailed to randomly selected ENA members. Subjects were asked to rate items on the size, frequency, and manitude of obstacles and supportive behaviors that relate to end-of-life care for ED patients.

Results: The perceived obstacles with the greatest magnitude were as follows: (a) ED nurses' work loads being too high to allow adequate time for patient care, (b) poor design of emergency departments, and (c) family members not understanding what "life-saving measures" really mean.

The three highest-scoring supportive behaviors were as follows: (a) allowing family members adequate time to be alone with the patient after he or she has died; (b) having good communication between the physician and $\mathrm{RN}$; and (c) providing a peaceful, dignified bedside scene for family members once the patient has died.

Renea L. Beckstrand, Timpanogos Chapter, is Associate Professor, Brigham Young University, Provo, Utah.

Michelle D. Smith, Timpanogos Chapter, is Nurse Practitioner, Pediatric Care, Provo, Utah.

Sondra Heaston, Northern Utah Chapter, is Assistant Teaching Professor, Brigham Young University, Provo, Utah.

A. Elaine Bond is Associate Professor, University of Jordan, Amman, Jordan. Supported in part by Brigham Young University, Provo, Utah.

For correspondence, write: Renea L. Beckstrand, PhD, RN, CCRN, Brigham Young University, College of Nursing, 422 SWKT, PO Box 25432, Provo, UT 84602-5432; E-mail: renea_beckstrand@byu.edu.

J Emerg Nurs 2008;34:290-300.

Available online 11 June 2008.

0099-1767/\$34.00

Copyright (C) 2008 by the Emergency Nurses Association.

doi: 10.1016/j.jen.2007.09.004
Discussion: It is hoped that the results of this study will help increase and facilitate the discussions regarding end-of-life care in emergency departments. Realistic initial implications include finding ways to decrease workloads of emergency nurses and increase direct patient care. Another important implication would be the improvement of ED designs. Further research in the area of end-of-life care in emergency settings is recommended.

W hile death is an inevitable part of life, it often is viewed as an unwanted event. In 2002, an estimated 272,000 patients either died in emergency departments across America or were pronounced dead on arrival at emergency departments. ${ }^{1}$ As America's population ages, it is suspected that this large number of dying patients in emergency departments will continue to increase. Emergency nurses are the ones who know first-hand what actions are needed to improve end-of-life (EOL) care for dying patients.

Nurses and other health care professionals generally receive education about healing and curing patients more than about preparing patients and families for the outcome of death. Unfortunately, focusing only on healing and curing, such as in an emergency setting, could coincide with a lack of appropriate care for patients as they approach the EOL. At times, emergency nurses must look beyond curing and resuscitation efforts to focus on the care and comfort of the patient who is at the EOL. ${ }^{2}$

Because of the large number of dying patients in emergency departments, it is vital that emergency nurses be prepared to care for dying patients and their families. Studying the obstacles that stand in the way of providing optimal EOL care while also determining the supportive behaviors that assist in providing increased quality of care to dying patients will improve EOL care in emergency departments. Furthermore, an evaluation of the frequency of occurrence of these obstacles and supportive behaviors will help prioritize which behaviors have the largest impact or magnitude and need to be reduced or eliminated and which behaviors need to be supported to optimize care at 
the EOL. While it is not possible to avoid or prevent all patient deaths, emergency nurses can make strides toward improving EOL care for patients and their families.

\section{Background and Significance}

While a few studies have been recently published on the obstacles and supportive behaviors in EOL care as perceived by critical care nurses, ${ }^{3-5}$ a literature review demonstrated a limited amount of research regarding EOL care in emergency departments. McClain and Perkins ${ }^{2}$ deemed issues related to physical symptoms, resuscitation mandates, and cultural and religious practices to be important to patients who were at the EOL in emergency departments. Baren and Mahon ${ }^{6}$ stated that an informed, structured, and empathetic approach by emergency staff is important to patients and their families in pediatric emergencies. They also noted that communication, palliation, and education also have been reported as supportive behaviors in emergency settings. Because it has been stated that death occurs more often in emergency environments than in other health care settings, ${ }^{6}$ EOL care in emergency settings is an area that needs further research.

Although there is research regarding the major obstacles and supportive behaviors in providing EOL care in emergency departments as perceived by emergency nurses, ${ }^{7}$ no reports were found that provided information combining the frequency and intensity of specific obstacles or supportive behaviors related to EOL care in emergency departments. Further, it is not known how frequently these listed obstacles and supportive behaviors occur. Therefore, there is a need to determine which obstacles and supportive behaviors regarding EOL care have the largest impact on patient care as perceived by emergency nurses.

\section{Research Questions}

Two research questions were addressed in this study. They were:

1. What are the size, frequency, and magnitude of selected obstacles in providing EOL care in emergency departments as perceived by emergency nurses?

2. What are the size, frequency, and magnitude of selected supportive behaviors in providing EOL care in emergency departments as perceived by emergency nurses?

\section{Methodology}

\section{SUBJECTS}

Institutional Review Board approval was obtained for this study. A random sample of 700 emergency nurses was obtained from the national ENA. As of December 2005, the ENA membership totaled $28,724,{ }^{8}$ so this 700 -member sample represented approximately $2.4 \%$ of the total ENA membership. This sample was deemed to be appropriate because it exceeded $2 \%$ of the total ENA membership and was a randomly selected national sample of emergency nurses.

ENA members who were considered eligible for the study had worked, at some time, in an emergency department, lived in the United States, were able to read English, and had cared for at least one patient at the EOL in an emergency setting. Consent to participate was assumed upon return of the questionnaire.

\section{INSTRUMENT}

The current instrument was adapted from a questionnaire utilized in another study on emergency nurses' perceptions of EOL care. ${ }^{7}$ The results from the study by Heaston et $\mathrm{al}^{7}$ were reviewed, and the current questionnaire was revised. Three items were deleted from the questionnaire used in Heaston's article because they received the lowest mean scores out of 28 listed obstacle items. The 3 deleted items were: (1) the nurse knowing about the patient's prognosis before the family is told the prognosis $(\mathrm{M}=1.63, \mathrm{SD}=$ $1.66)$; (2) continuing to provide advanced treatments to dying patients because of financial benefits to the hospital $(\mathrm{M}=$ $1.80, \mathrm{SD}=1.92)$; and (3) physicians who are overly optimistic to the family about the patient surviving $(\mathrm{M}=2.03, \mathrm{SD}=1.39)$.

A similar process of evaluation and elimination of the study's two lowest scoring supportive behavior items was completed. ${ }^{7}$ The supportive behavior items deleted were: (1) physicians who put hope in real tangible terms by saying to the family that, for example, only 1 out of 100 patients in this patient's condition will completely recover $(\mathrm{M}=3.29$, $\mathrm{SD}=1.56$ ); and (2) having unlicensed personnel available to help care for dying patients $(\mathrm{M}=3.45, \mathrm{SD}=1.47)$.

Suggestions from participants in the original study ${ }^{7}$ also were considered in formulating 3 new supportive behavior items included in the current questionnaire. The new supportive behavior items that were added were: (1) an emergency department designed to provide privacy for the dying patient; (2) nurses receiving education to give appropriate EOL care to patients and their families; and (3) nurses' having the opportunity to participate in a debriefing session after a traumatic death. Once all new revisions were completed, the current questionnaire contained 70 items, 51 of which had Likert-type response options.

\section{PROCEDURE}

Participant mailing information was obtained from ENA. Prior to mailing the questionnaires, each participant was 
assigned a numerical code to ensure confidentiality. Subjects then received a letter of explanation, a copy of the questionnaire, and a self-addressed stamped return envelope. Two follow-up mailings followed the first mailing. Included in the subsequent mailings was a new cover letter, a copy of the survey, and a self-addressed stamped return envelope. Participants also were invited to complete an identical copy of the survey that was placed on an online survey Web site. Results then were compiled and data were entered into SPSS software (SPSS, Inc, Chicago, IL). All responses were then evaluated and analyzed.

\section{Results}

\section{DEMOGRAPHIC DATA}

Of the 700 potential respondents, 384 questionnaires were returned. Of the 384 returned responses, 112 were eliminated from the study sample either because the recipients reported that they were ineligible $(\mathrm{n}=95)$ or because the questionnaire could not be delivered $(\mathrm{n}=17)$. The primary reason given for ineligibility was that respondents were not currently working as a registered nurse (RN) in an emergency department and did not feel qualified to complete the survey. Usable responses were received from 272 nurses for a response rate of $46.3 \%$ after 3 mailings. ${ }^{9}$ Demographic information is shown in Table 1.

\section{OBSTACLE MAGNITUDE}

All items in the obstacle section of the questionnaire were ranked by participants in areas of both size and frequency. The scale utilized for obstacle size ranged from 0 (not an obstacle) to 5 (extremely large obstacle). A similar scale of 0 (never occurs) to 5 (always occurs) was used for scoring obstacle frequencies. There were 28 obstacle items. A rating of the obstacle's magnitude or impact was determined by multiplying each obstacle's mean score by that obstacle's mean frequency score to obtain a Perceived Obstacle Magnitude (POM) score. ${ }^{4,10}$ The highest possible POM score would have been 11.45 if the highest obstacle size mean had been multiplied by the highest obstacle frequency mean. For the 28 rated obstacles, the POM scores actually ranged from 11.34 to 2.73. The 3 highest POM score obstacles were: (1) the ED nurse having too high a work load to allow adequate time to care for dying patients and their families $(\mathrm{POM}=11.34)$; (2) poor design of emergency departments not allowing for privacy of dying patients or grieving family members (POM = 11.01); and (3) family members not understanding what "life-saving measures" really mean, that is, that multiple needle sticks cause pain and bruising, that an endotracheal tube will not allow the patient to talk, or that ribs may be broken during chest compressions (POM $=10.05)$.
The 3 obstacles with lowest POM scores were: (1) too many family members in the room during resuscitation $(\mathrm{POM}=2.73)$; (2) the nurse not being comfortable caring for the dying patient $(\mathrm{POM}=3.95)$; and $(3)$ when the nurse's opinion about the direction patient care should go is not requested, not valued, or not considered $(\mathrm{POM}=$ 4.48) (Table 2).

\section{SUPPORTIVE BEHAVIOR MAGNITUDE}

The Perceived Supportive Behavior Magnitude (PSBM) scores were obtained by multiplying each supportive behavior item's mean size by the item's mean frequency. ${ }^{4,10}$ The highest possible PSBM score would have been 15.87 if the highest supportive behavior item's mean had been multiplied by the highest supportive behavior item's mean. The PSBM scores were higher than the magnitude scores of the obstacles. The PSBM scores for this study ranged from a high of 15.69 to a low of 6.45 .

The 3 highest scoring supportive behaviors were: (1) allowing family members adequate time to be alone with the patient after he or she had died (PSBM = 15.69); (2) having good communication between the physician and $\mathrm{RN}$ who are caring for the dying patient (PSBM = 14.75); and (3) providing a peaceful, dignified bedside scene for family members once the patient has died $(\mathrm{PSBM}=14.71)$.

The 3 lowest scoring supportive behaviors were: (1) the opportunity to participate in a professional debriefing session after a traumatic death (PSBM $=6.45)$; (2) talking with the patient about his or her feelings and thoughts about dying (PSBM = 6.63); and (3) having enough time to prepare the family for the expected death of a patient $(\mathrm{PSBM}=8.41)($ Table 3$)$.

\section{Discussion}

\section{COMPARISONS BETWEEN CURRENT AND} PREVIOUS STUDIES

Significant similarities were found between the current study, the original study, ${ }^{7}$ and the previous study of critical care nurses' perceptions of EOL care. ${ }^{4}$ The 8 highest ranked obstacles from this current study were also the top 8 ranked obstacles in size in the study by Heaston et al. ${ }^{7}$ Of the highest 10 ranked obstacles in this study, 7 also were ranked in the top 10 from the previous study of critical care nurses by Beckstrand and Kirchhoff. ${ }^{4}$

Strong similarities between the current study and the original study ${ }^{7}$ continued in the supportive behaviors area. When comparing the current study's top 10 scoring supportive behaviors with the top 10 supportive behaviors from Beckstrand and Kirchhoff's survey of critical 
TABLE 1

Demographics of nurses*

Characteristic

Sex

Male

Female

Did not report

Age

Years as RN

Years in ED

Hours worked/wk

No. of ED beds in unit

Dying patients cared for

$$
>30
$$

21-30

11-20

$\leq 10$

Highest degree

Diploma

Associate

Bachelor

Master

Doctoral

Ever CEN

Yes

No

Currently CEN

Yes

No

No answer

Years as CEN

Practice area

Adult/pediatrics

Adults only

Pediatrics only

Hospital type

Nonprofit, community

University medical centers

For profit, community

Other
N (\%)

Mean

SD

Range

$39(14.3 \%)$

$230(84.6 \%)$

$3(1.1 \%)$

47.3

9.5

10.6

8.9

13.9

27.7

27.0

14.7

26-72

$1-45$

$1-40$

0-75

$0-76$
$74.6 \%$

$10.1 \%$

$10.8 \%$

$4.5 \%$

$11.5 \%$

$24.2 \%$

$43.5 \%$

$20.5 \%$

$.4 \%$

$59.2 \%$

$40.8 \%$

$40.8 \%$

$20.2 \%$

$39.0 \%$

9.8

6.7

4 mo-26 y
$90.0 \%$

$8.1 \%$

$1.9 \%$

$64.7 \%$

$9.6 \%$

$12.5 \%$

$13.2 \%$

$C E N$, Certified emergency nurse; $R N$, registered nurse; $S D$, standard deviation

${ }^{*} \mathrm{~N}=384$ returned, 272 usable, 112 not eligible; $46.3 \%$ response rate after 3 mailings. 
TABLE 2

Intensity mean, standard deviation, and rank; frequency mean, standard deviation, and rank; and perceived obstacle magnitude for obstacles in end-of-life care

Obstacles

The ED nurse having too high a work load to allow for adequate time to care for dying patients and their families

Poor design of emergency departments that do not allow for privacy of dying patients or grieving family members

Family members not understanding what "life-saving measures" really mean, ie, that multiple needle sticks cause pain and bruising, that an ET tube won't allow the patient to talk, or that ribs may be broken during chest compressions

Not enough time to provide quality end-of-life care because the nurse is consumed with activities that are trying to save the patient's life

The nurse having to deal with distraught family members while still providing care for the patient

Family and friends who continually call the nurse wanting an update on the patient's condition rather than calling the designated family member for information

The nurse having to deal with angry family members The nurse not knowing the patient's wishes regarding continuing with treatments and tests because of the inability to communicate due to a depressed neurologic status or pharmacologic sedation

Being called away from the patient and his or her family because of the need to help with a new admit or to help another nurse care for his/her patients

Physicians who order unnecessary tests or procedures for dying patients just so they can say that every possibility was considered

Families not accepting what the physician is telling them about the patient's poor prognosis

Physicians who avoid having conversations with family members

The family, for whatever reason, is not with the patient when he or she is dying

Restriction of family members in the ED room during resuscitation

Pressure to limit family grieving after the patient's death to accommodate a new admit to that room Intra-family disagreements about whether to approve the use of life support

\begin{tabular}{|c|c|c|c|c|c|c|}
\hline $\begin{array}{c}\text { Intensity } \\
\mathrm{M}^{*}\end{array}$ & $\begin{array}{l}\text { Intensity } \\
\text { SD }\end{array}$ & $\begin{array}{l}\text { Intensity } \\
\text { rank }\end{array}$ & $\begin{array}{l}\text { Frequency } \\
\qquad \mathbf{M}^{\dagger}\end{array}$ & $\begin{array}{c}\text { Frequency } \\
\text { SD }\end{array}$ & $\begin{array}{c}\text { Frequency } \\
\text { rank }\end{array}$ & $\mathrm{POM}^{\ddagger}$ \\
\hline 3.67 & 1.22 & 1 & 3.09 & 1.26 & 2 & 11.34 \\
\hline 3.53 & 1.38 & 3 & 3.12 & 1.38 & 1 & 11.01 \\
\hline 3.50 & 1.22 & 4 & 2.87 & 1.23 & 4 & 10.05 \\
\hline 3.42 & 1.17 & 5 & 2.84 & 1.09 & 5 & 9.71 \\
\hline 3.24 & 1.15 & 8 & 2.97 & 3.36 & 3 & 9.62 \\
\hline 3.33 & 1.35 & 7 & 2.83 & 1.31 & 6 & 9.42 \\
\hline 3.56 & 1.11 & 2 & 2.64 & 1.02 & 8 & 9.40 \\
\hline 3.35 & 1.25 & 6 & 2.66 & 1.11 & 7 & 8.91 \\
\hline
\end{tabular}

$\begin{array}{lllllll}3.08 & 1.36 & 11 & 2.57 & 1.26 & 9 & 7.92\end{array}$

$\begin{array}{lllllll}3.10 & 1.33 & 10 & 2.36 & 1.21 & 12 & 7.32\end{array}$

$\begin{array}{rrrrrrr}2.96 & 1.15 & 14 & 2.39 & 0.90 & 11 & 7.07 \\ 3.21 & 1.44 & 9 & 2.11 & 1.11 & 17 & 6.77 \\ 2.89 & 1.22 & 15 & 2.30 & 0.96 & 13 & 6.65 \\ 2.51 & 1.49 & 25 & 2.55 & 1.44 & 10 & 6.40 \\ 2.83 & 1.50 & 17 & 2.21 & 1.33 & 14 & 6.25 \\ 3.00 & 1.29 & 13 & 2.06 & 0.90 & 19 & 6.18\end{array}$


TABLE 2 (continued)

\begin{tabular}{|c|c|c|c|c|c|c|c|}
\hline Obstacles & $\begin{array}{l}\text { Intensity } \\
\mathbf{M}^{*}\end{array}$ & $\begin{array}{l}\text { Intensity } \\
\text { SD }\end{array}$ & $\begin{array}{l}\text { Intensity } \\
\text { rank }\end{array}$ & $\begin{array}{l}\text { Frequency } \\
\qquad \mathbf{M}^{+}\end{array}$ & $\begin{array}{l}\text { Frequency } \\
\text { SD }\end{array}$ & $\begin{array}{l}\text { Frequency } \\
\text { rank }\end{array}$ & $\mathrm{POM}^{\ddagger}$ \\
\hline $\begin{array}{l}\text { The patient having pain that is difficult to control } \\
\text { or alleviate }\end{array}$ & 2.83 & 1.23 & 16 & 2.11 & 0.96 & 18 & 5.97 \\
\hline $\begin{array}{l}\text { Using life-sustaining measures at the families' } \\
\text { request even though the patient had signed } \\
\text { advanced directives requesting no such treatment }\end{array}$ & 3.04 & 1.58 & 12 & 1.90 & 1.10 & 23 & 5.78 \\
\hline $\begin{array}{l}\text { Providing treatments for a dying patient even } \\
\text { though the treatments cause the patient pain } \\
\text { or discomfort }\end{array}$ & 2.82 & 1.33 & 18 & 2.03 & 1.04 & 21 & 5.72 \\
\hline $\begin{array}{l}\text { Lack of nursing education and training regarding } \\
\text { family grieving and quality end-of-life care }\end{array}$ & 2.55 & 1.49 & 22 & 2.21 & 1.31 & 15 & 5.64 \\
\hline $\begin{array}{l}\text { Dealing with the cultural differences that families } \\
\text { employ in grieving for their dying family member }\end{array}$ & 2.56 & 1.18 & 21 & 2.18 & 0.97 & 16 & 5.58 \\
\hline $\begin{array}{l}\text { Physicians who won't allow the patient to die } \\
\text { from the disease process }\end{array}$ & 2.68 & 1.54 & 20 & 1.95 & 1.18 & 22 & 5.23 \\
\hline $\begin{array}{l}\text { No available support person for the family such } \\
\text { as a social worker or religious leader }\end{array}$ & 2.52 & 1.59 & 24 & 2.04 & 1.41 & 20 & 5.14 \\
\hline $\begin{array}{l}\text { Multiple physicians, involved with one patient, who } \\
\text { differ in opinion about the direction care should go }\end{array}$ & 2.77 & 1.58 & 19 & 1.75 & 1.13 & 27 & 4.85 \\
\hline $\begin{array}{l}\text { Continuing resuscitation for a patient with a poor } \\
\text { prognosis because of the real or imagined threat } \\
\text { of future legal action by the patient's family }\end{array}$ & 2.54 & 1.49 & 23 & 1.77 & 1.13 & 26 & 4.50 \\
\hline $\begin{array}{l}\text { When the nurse's opinion about the direction } \\
\text { patient care should go is not requested, not } \\
\text { valued, or not considered }\end{array}$ & 2.46 & 1.45 & 26 & 1.82 & 1.10 & 25 & 4.48 \\
\hline $\begin{array}{l}\text { The nurse not being comfortable caring for the } \\
\text { dying patients and/or their families }\end{array}$ & 2.10 & 1.44 & 28 & 1.88 & 0.93 & 24 & 3.95 \\
\hline $\begin{array}{l}\text { Too many family members being allowed in the } \\
\text { room during resuscitation }\end{array}$ & 2.17 & 1.60 & 27 & 1.26 & 1.03 & 28 & 2.73 \\
\hline
\end{tabular}

$E T$, Endotracheal; $M$, mean; $P O M$, perceived obstacle magnitude; $S D$, standard deviation. * Intensity of obstacle response choices were: $0=$ Not an obstacle to $5=$ Extremely intense.

${ }^{\dagger}$ Frequency of obstacle response choices were: $0=$ Never occurs to $5=$ Always occurs.

${ }^{\ddagger} \mathrm{POM}=$ Perceived Obstacle Magnitude (obstacle intensity M multiplied by obstacle frequency M).

care nurses ${ }^{4}$ and the study by Heaston et al, ${ }^{7}$ each of the 2 previous studies had 7 of the top 10 ranked supportive behaviors, which were the same as in the current study.

The strong similarity between the highest ranking items in these 3 studies demonstrates that many issues regarding EOL care in hospital settings may be universal. While each department may have some specific and unique challenges, EOL care of patients and families brings similar issues related to the emotional nature of a loved one dying and the fact that the same people (patient, family, nurse, and physician) are involved regardless of the actual location of the department.

In reviewing the results of all 3 studies, the greatest obstacles to providing EOL care in either critical care or emergency hospital settings seem to be related to issues involving nurses' high work loads, hospital unit designs, families of dying patients, and poor communications.

\section{OBSTACLE RESULTS}

The obstacle receiving the largest magnitude score was the emergency nurse having work loads too high to allow adequate time to care for dying patients and their families. This sentiment is supported by ENA, which has found the issue of staffing and productivity in the emergency setting to be an important issue, as evidenced by their position statement that was developed as early as 1987 and was revised as recently as $2003 .^{11}$ This position statement is based on research that has shown that nurse staffing rates 
TABLE 3

Intensity mean, standard deviation, and rank; frequency mean, standard deviation, and rank; and perceived supportive behavior magnitude for supportive behaviors in end-of-life care

\section{Supportive behaviors}

Intensity Intensity Intensity Frequency Frequency Frequency

Allowing family members adequate time to be alone with the patient after he or she has died

Good communication between the physician and $\mathrm{RN}$ who are caring for the dying patient

Providing a peaceful, dignified bedside scene for family members once the patient has died

Having the physicians involved in the patient's care agree about the direction care should go

Teaching families how to act around the dying patient such as saying to them, "She can still hear...it is OK to talk to her"

An emergency department designed so that the family has a place to grieve in private

Having family members accept that the patient is dying

Letting the social worker, nursing supervisor, or religious leader take primary care of the grieving family

Allowing families unlimited access to the dying patient even if it conflicts with nursing care at times

The nurse drawing on his/her own previous experience with the critical illness or death of a family member

Having a fellow nurse tell you that, "You did all you could for that patient," or some other words of support

Having family members thank you or in some other way show appreciation for your care of the patient who has died

EMT/paramedic personnel assisting with resuscitation efforts on the dying patient

Having one family member be the designated contact person for all other family members regarding patient information

An emergency department designed to provide privacy for the dying patient

After the patient's death, having support staff compile all the necessary paper work for you which must be signed by the family before they leave the department

Having fellow nurses take care of your other patient(s) while you get away from the department for a few moments after the death of your patient

\begin{tabular}{|c|c|c|c|c|c|c|}
\hline $\mathbf{M}^{*}$ & SD & rank & $\mathbf{M}^{\dagger}$ & SD & rank & PSBM $^{\ddagger}$ \\
\hline 4.51 & .71 & 2 & 3.48 & 1.17 & 1 & 15.69 \\
\hline 4.51 & .74 & 3 & 3.27 & .98 & 4 & 14.75 \\
\hline 4.47 & .73 & 5 & 3.29 & 1.24 & 3 & 14.71 \\
\hline 4.37 & .75 & 7 & 3.19 & .99 & 5 & 13.94 \\
\hline 4.23 & .87 & 11 & 3.29 & 1.03 & 2 & 13.92 \\
\hline 4.56 & .72 & 1 & 2.65 & 1.49 & 12 & 12.08 \\
\hline 4.49 & .71 & 4 & 2.66 & .81 & 11 & 11.94 \\
\hline 4.29 & .81 & 8 & 2.72 & 1.27 & 10 & 11.67 \\
\hline 3.83 & 1.19 & 18 & 3.01 & 1.11 & 6 & 11.53 \\
\hline 3.79 & 1.19 & 19 & 2.98 & 1.14 & 7 & 11.29 \\
\hline 3.78 & 1.25 & 20 & 2.78 & 1.17 & 8 & 10.51 \\
\hline 4.26 & .89 & 10 & 2.42 & 1.05 & 13 & 10.31 \\
\hline 3.58 & 1.34 & 22 & 2.72 & 1.28 & 9 & 9.74 \\
\hline 4.27 & .93 & 9 & 2.23 & .96 & 16 & 9.52 \\
\hline 4.44 & .80 & 6 & 2.13 & 1.37 & 17 & 9.46 \\
\hline 4.22 & 1.01 & 12 & 2.13 & 1.41 & 18 & 8.99 \\
\hline 4.13 & 1.06 & 14 & 2.10 & 1.33 & 19 & 8.67 \\
\hline
\end{tabular}


TABLE 3 (continued)

Supportive behaviors

Having a support person outside of the work

setting who will listen to you after the death of your patient

Receiving education necessary to give appropriate end-of-life care to patients and their families

Having a fellow nurse put his or her arm around you, hug you, pat you on the back or give some other kind of brief physical support after the death of your patient

Having enough time to prepare the family for the expected death of the patient

Talking with the patient about his or her feelings and thoughts about dying

The opportunity to participate in a professional debriefing session after a traumatic death

Intensity Intensity Intensity Frequency Frequency Frequency

$\begin{array}{ccccccr}\mathbf{M}^{*} & \text { SD } & \text { rank } & \mathbf{M}^{\dagger} & \text { SD } & \text { rank } & \text { PSBM } \\ 3.74 & 1.27 & 21 & 2.30 & 1.61 & 15 & 8.60\end{array}$

4.15

.94

13

2.06

1.22

20

8.55

3.57

1.41

23

2.39

1.33

14

8.53

\subsection{0}

.91

15

2.05

.91

21

3.88

1.07

16

1.71

.92

EMT, Emergency medical technician; $M$, mean; $P S B M$, perceived supportive behavior magnitude; $R N$, registered nurse; $S D$, standard deviation.

*Intensity of helpful behavior response choices were: $0=$ Not a help to $5=$ Extremely intense.

${ }^{\dagger}$ Frequency of helpful behavior response choices were: $0=$ Never occurs to $5=$ always occurs.

${ }^{\ddagger}$ PSBM $=$ Perceived Supportive Behavior Magnitude (Behavior intensity M multiplied by frequency M).

influence patient outcomes. ${ }^{11}$ ENA's position statement indicates that managers and administrators have a responsibility for ensuring effective and efficient delivery of emergency care through appropriate staffing of emergency departments. This position statement by ENA also notes that adequate and efficient staffing of nurses and ancillary staff is essential in delivering quality, cost efficient care. ENA also supports further research regarding ED staffing and encourages utilization of the ENA Guidelines for Emergency Department Nurse Staffing. ${ }^{11}$

A 3-year study by Hobgood, Villani, and Quattlebaum ${ }^{12}$ also found that emergency nurses currently spend approximately half as much time providing direct bedside patient care, compared with twice as much time spent in indirect patient care (eg, charting, making phone calls, and traveling to/from patient rooms). System changes that allow nurses to spend increased amounts of time providing direct patient care and less time in indirect patient care are needed. ${ }^{22}$ While the subject of high nursing workloads encompasses many difficult issues, including nursing shortages, economics, and health care systems, the issue of emergency nurses being understaffed and overworked needs to be addressed.

Poor design of emergency departments that do not allow for privacy of dying patients or grieving family members was found to be the second highest ranked obstacle to giving EOL care in emergency departments. Nurses are not the only ones who believe this issue is important. The need to improve ED design has been noticed by leading health care construction companies and leading hospital executives. ${ }^{13}$ Many new hospitals are discovering economical ways to utilize expert hospital development companies in building facilities. ${ }^{13}$ Visitor-friendly and patient-friendly additions made to some newly constructed hospitals include more private rooms for patients and multiple family suites that provide family members with private, comfortable waiting areas. ${ }^{13}$ Building medical facilities represents the opportunity to combine the latest in technology, design, information systems and medicine to provide the best possible care. Many of those who are planning and designing emergency departments acknowledge the need for collective input and work of many individuals. ${ }^{14} \mathrm{~A}$ recent study conducted in a redesigned emergency department found that improving the physical environment in which patients are treated increased patient and family satisfaction. ${ }^{15}$ This same study also found an increase in staff confidence and staff satisfaction in the newly remodeled department. Also, Hobgood et $\mathrm{al}^{12}$ raise the issue of ED design and layout relating to nursing efficiency and transit times. More research toward improving ED designs is encouraged. 
Of the 7 highest ranked obstacles, emergency nurses reported 4 to be related to issues regarding family members. They were: (1) family members not understanding what "life saving measures" really means; (2) the nurse having to deal with distraught family members; (3) family members calling the nurse regarding patient status; and (4) the nurse having to deal with angry family members. Family issues may be perceived to be a large obstacle by emergency nurses because of a nurse's desires to provide excellent care for the dying patient, while each of these 4 obstacles takes the nurse away from care of the patient. For example, because of the chaotic and fast-paced emergency environment, emergency nurses may have only a relatively brief amount time to spend explaining patient situations or terminology to families. ${ }^{16}$ This time taken to educate families or keep them appraised of the current situation decreases the amount of time the nurse can care for the patient. However, this limited time to communicate with families is crucial. While the nurse may have very little time to speak with the family, the patient's family may have a lifetime to remember the words, actions, decisions, and nursing care given at a loved one's death. ${ }^{16}$

The 2 lowest scoring obstacles in this study were the nurse not feeling comfortable caring for the dying patient and/or their family and too many family members being allowed in the room during resuscitation. These also ranked in the lowest 3 obstacles that remained from the original study. The item regarding nurses feeling comfortable caring for dying patients was most likely the lowest scoring obstacle because this sample included a large number of very experienced emergency nurses. These nurses have come to feel comfortable caring for all types of emergency patients.

Regarding family members in the resuscitation room, it may be possible that this item received a low POM score because family members are not always allowed to be in the room during resuscitation or there are regional differences with this practice; therefore, family presence may not be an issue. It also is possible that emergency nurses do not perceive family presence to be an obstacle because emergency nurses support this issue. ENA's educational push and position statement, written in 1993, stresses the importance of family members being allowed to view resuscitations. ${ }^{17}$ Much research has been done regarding the effects of family presence during resuscitation. Historical concerns of potential distraction of the health care provider and possible harm to the patient or family members have been refuted. ${ }^{18}$ Instead of criticizing care, family members who were allowed to witness resuscitation believed that everything possible was done for the patient. ${ }^{18}$ Disruptions in patient care and litigations by family members were not increased through family presence during resuscitation. ${ }^{18}$ Most family members believed that being present during resuscitation had a positive impact on grieving and the family members would choose to be present again if given the option. ${ }^{18}$

\section{SUPPORTIVE BEHAVIOR RESULTS}

The highest and third-highest scoring supportive behaviors were (1) allowing family members adequate time to be alone with the patient after he or she has died and (2) providing a peaceful, dignified bedside scene for family members once the patient has died. Both of these supportive behaviors are related to caring actions toward families after a patient's death. These behaviors probably are seen as having a high supportive magnitude by emergency nurses because these nurses can control the occurrence and frequency of these actions.

The second-highest scoring supportive behavior was good communication between the physician and RN who are caring for the dying patient. Safe, efficient, and effective patient care correlates with a stable foundation of nurse-physician communication. ${ }^{19}$ As partners in patient care, nurses and physicians can greatly influence patient outcomes. In fact, studies have linked effective, frequent nurse-physician communication with patient survival in ICUs. ${ }^{19-21}$ Poor nurse-physician communication has been associated with medication errors, patient injuries, and patient deaths. ${ }^{19}$ Open, trusting lines of communication may be especially beneficial in emergency departments where nurses and physicians work side by side during multiple, long shifts.

The majority of the top 10 supportive behaviors could be related to facilitating grieving by family members or to the importance of an experienced medical team working together. The supportive behavior items relating to family members included allowing time alone with the patient after death; providing a peaceful, dignified bedside scene; teaching families how to act around the dying patient; designing an emergency department with a place for families to grieve in private; having family members accept that the patient is dying; and allowing family members unlimited access to the dying patient even if it conflicts with nursing care. These highly rated supportive behaviors show the depth of concern emergency nurses have for patients and their family members.

The 3 highest rated supportive behavior items related to the importance of teamwork by those caring for the dying patient were: (1) having good communication between the physician and RN caring for the patient; (2) having all the physicians involved agree about the direction of care; and (3) letting the social worker, nursing 
supervisor, or religious leader take primary care of the grieving family. Agreeing about the direction of care is seen as a supportive behavior because the nurse is not caught in the middle of disagreeing physicians, which allows him or her to spend more time on patient care. At first glance, having a social worker, nursing supervisor, or religious leader take primary care of the grieving family may sound as if the emergency nurse were abdicating his or her responsibility toward the patient's family. However, this behavior probably was highly rated because, at the moment of crisis, allowing others to assume one-to-one responsibility for the patient's angry or upset family members gives the ED nurse the opportunity to focus completely on resuscitation and/ or care of the dying patient. The emergency nurse may then resume care of the patient's family once the crisis situation has resolved.

The lowest scoring supportive behavior was related to professional debriefing sessions. This behavior also ranked the very lowest in frequency of occurrence. Even though this supportive behavior item was added at the suggestion of the nurses participating in the original study, it may not be considered helpful because it is not happening often or because these nurses have learned to continue to work even after the emotions of experiencing patient deaths.

The next 2 lowest ranked supportive behaviors were related to communicating with the patient and family regarding an anticipated death. It is interesting to note that while these behaviors may be plausible in the ICU, talking with patients regarding their feelings about death and having enough time to prepare the family for a patient's death are not occurring frequently in emergency settings. Beckstrand and Kirchhoff ${ }^{4}$ reported that having enough time to prepare the family for a patient's death and talking with the patient about death were perceived by critical care nurses to be highly supportive behaviors compared with the current study of ED nurses. However, the emergency department often is considered a place of transition; the deaths taking place there are often rapid, traumatic, and unexpected. Currently, ED nurses may not have time to form bonds with dying patients or to prepare themselves emotionally for a death in the emergency department. Emergency nurses must be prepared at all times because they cannot anticipate what may happen at any moment.

\section{Conclusion/Limitations/Implications}

The purposes of this study were to determine a magnitude score for both obstacles and supportive behaviors surrounding EOL care in emergency departments. Although the respondents represent only a small percentage of ENA members, the sample was randomly selected with a good response rate and so can be generalized to members of ENA.

It is hoped that the results of this study will help facilitate discussions regarding EOL care in emergency departments. Further, the highest scoring obstacles can be evaluated to determine improvements that can be implemented to decrease or eliminate these obstacles in providing EOL care to dying patients. Realistic initial implications, for example, include finding ways to decrease work loads of emergency nurses and increase direct patient care. Another important implication would be the improvement of ED designs, using specific valuable suggestions from ED staff members. It is anticipated that private and calm areas could be available for dying patients and their families.

Conversely, the top supportive behaviors can guide nurses as they provide EOL care. Lower scoring supportive behaviors should be examined to determine if their scores can somehow be increased. For example, ways to increase frequency of nurse education in appropriate EOL care could possibly increase the magnitude of this item in future studies. It is anticipated that these changes will then lead to a more comfortable and improved experience for emergency patients and their families. Further research is needed into ways to decrease obstacles with the highest magnitude and increase high magnitude supportive behaviors.

\section{REFERENCES}

1. McCaig LF, Burt CW. National hospital ambulatory medical care survey: 2002 emergency department summary. Advance data from vital and health statistics (No. 340). Hyattsville (MD): National Center for Health Statistics; 2004.

2. McClain K, Perkins P. Terminally ill patients in the emergency department: a practical overview of end-of-life issues. J Emerg Nurs 2002;28:515-22.

3. Beckstrand RL, Callister LC, Kirchhoff KT. Providing a "good death": critical care nurses' suggestions for improving end-of-life cares. Am J Crit Care 2006;15:38-46.

4. Beckstrand RL, Kirchhoff KT. Providing end-of-life care to patients: critical care nurses' perceived obstacles and supportive behaviors. Am J Crit Care 2005;14:395-403.

5. Kirchhoff KT, Beckstrand RL. Critical care nurses' perceptions of obstacles and helpful behaviors in providing end-of-life care to dying patients. Am J Crit Care 2000;9:96-105.

6. Baren JM, Mahon M. End-of-life issues in the pediatric emergency department. Clin Pediatr Emerg Med 2003;4:265-72.

7. Heaston S, Beckstrand RL, Bond AE, Palmer SP. Emergency nurses' perceptions of obstacles and supportive behaviors in end-of-life care. J Emerg Nurs 2006;32:477-85.

8. Howard PK. ENA highlights and accomplishments in 2005. ENA Connection 2005;29:1, 20.

9. Kirchhoff KT. Design of questionnaires and structured inter- 
view. In: Mateo MA, Kirchhoff KT, editors. Using and conducting nursing research in the clinical setting. 2nd ed. Philadelphia: W.B. Saunders Company; 1999.

10. Sawatzky JA. Stress in critical care nurses: actual and perceived. Heart Lung 1996;25:409-17.

11. Emergency Nurses Association. Emergency Nurses Association position statement: staffing and productivity in the emergency care setting. 1-6. Available at: http://www.ena.org/about/position/ PDFs/Staffing-Productivity.PDF. Accessed March 28, 2006.

12. Hobgood C, Villani J, Quattlebaum R. Impact of emergency department volume on registered nurse time at the bedside. Ann Emerg Med 2005;46:481-9.

13. Pinto C. 1998 Construction and design survey: ERs, international projects drawing more attention. Modern Healthcare 1998;28:1-39.

14. Flanagan T, Haas AJ. Planning a new emergency department from design to occupancy. J Ambulatory Care Manager 2005;28:177-81.

15. Judkins S. Paediatric emergency department design: does it affect staff, patient, and community satisfaction? Emerg Med 2003;15:63-7.
16. Knox C, Vereb JA. Allow natural death: a more humane approach to discussing end of-life directives. J Emerg Nurs 2005;31:560-1.

17. Emergency Nurses Association. Emergency Nurses Association position statement: resuscitative decisions. 1-3. Available at: http://www.ena.org/about/position/pdfs/resuscitativedecisions.pdf. Accessed March 28, 2006.

18. Henderson DP, Knapp JF. Report of the national consensus conference on family presence during pediatric cardiopulmonary resuscitation and procedures. J Emerg Nurs 2006;32: 23-9.

19. Arford PH. Nurse-physician communication: an organizational accountability. Nurs Economic\$2005;23:72-7.

20. Baggs JC, Schmitt MH, Mushlin AI, Mitchell PH, Eldredge $\mathrm{DH}$, Oakes D, et al. Association between nurse-physician collaboration and patient outcomes in three intensive care units. Crit Care Med 1999;27:1991-8.

21. Knaus WA, Draper EA, Wagner DP, Zimmerman JE. An evaluation of outcomes from intensive care in major medical centers. Ann Intern Med 1986;104:410-8.

\section{Address Changes}

NOTIFY US 6 WEEKS PRIOR TO MOVING. USE ANY OF THE FOLLOWING OPTIONS.

\section{ENA Members}

ENA members have 3 options:

1. Phone: Call (800) 243-8362 toll-free between the hours of 8:00 AM and 5:00 PM (CT).

2. Internet: Log onto the ENA Web site at www.ena.org (click on the "Members" button, select "Forms" and then "Change form")

3. Fax: Our fax is available $24 / 7$ at (847) $460-4002$.

\section{Other Subscribers}

1. Phones: US/Canada: (800) 654-2452; Other Countries: (407) 345-4000

2. E-mail: elspcs@elsevier.com

3. Fax: (407) 363-9661

4. Or, mail to: Journal of Emergency Nursing Subscription Customer Service 6277 Sea Harbor Drive Orlando, FL 32887 